\title{
RNA expression and disease tolerance are associated with a "keystone mutation" in the ochre sea star Pisaster ochraceus
}

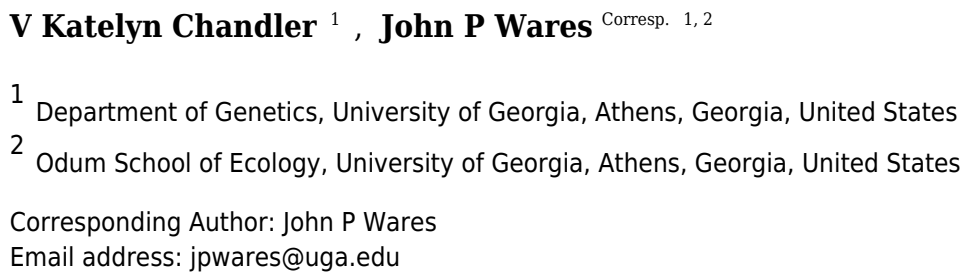

An overdominant mutation in an intron of the elongation factor 1- $\alpha$ (EF1A) gene in the sea star Pisaster ochraceus has shown itself to mediate tolerance to "sea star wasting disease", a pandemic that has significantly reduced sea star populations on the Pacific coast of North America. Here we use RNA sequencing of healthy individuals to identify differences in constitutive expression of gene regions that may help explain this tolerance phenotype. Our results show that individuals carrying this mutation have lower expression at a large contingent of gene regions. Individuals without this mutation also appear to have a greater cellular response to temperature stress, which has been implicated in the outbreak of sea star wasting disease. Given the ecological significance of P. ochraceus, these results may be useful in predicting the evolutionary and demographic future for Pacific intertidal communities. 
1 RNA expression and disease tolerance are associated with a 2 "keystone mutation" in the ochre sea star Pisaster ochraceus

3 V. Katelyn Chandler ${ }^{1}$

4 J.P. Wares ${ }^{1,2}$

5

$6{ }^{1}$ Department of Genetics, University of Georgia, Athens, Georgia, USA

7 20dum School of Ecology, University of Georgia, Athens, Georgia, USA

8

9 Corresponding Author: John Wares, jpwares@uga.edu 


\section{Abstract}

12 An overdominant mutation in an intron of the elongation factor 1- $\alpha(E F 1 A)$ gene in the sea

13 star Pisaster ochraceus has shown itself to mediate tolerance to "sea star wasting disease",

14 a pandemic that has significantly reduced sea star populations on the Pacific coast of North

15 America. Here we use RNA sequencing of healthy individuals to identify differences in

16 constitutive expression of gene regions that may help explain this tolerance phenotype. Our

17 results show that individuals carrying this mutation have lower expression at a large

18 contingent of gene regions. Individuals without this mutation also appear to have a greater

19 cellular response to temperature stress, which has been implicated in the outbreak of sea

20 star wasting disease. Given the ecological significance of P. ochraceus, these results may be

21 useful in predicting the evolutionary and demographic future for Pacific intertidal

22 communities. 


\section{Introduction}

25 The dynamics of an ecological community are often studied in terms of abundance and

26 interactions of the component "macro" diversity - predation, competition, parasitism, even

27 positive interactions among community members (Duffy \& Hay, 2001; Bruno, Stachowicz \&

28 Bertness, 2003; Vellend, 2016). Yet it is also clear that pathogens play immense roles in the

29 elimination of weaker or maladapted individuals, affecting density and behavior of infected

30 organisms, and even reshaping a community (Harvell et al., 2002; LoGiudice et al., 2003;

31 Mitchell \& Power, 2006; Stephens et al., 2016). Despite many early advances in community

32 ecology being derived from marine communities (Connell, 1961; Paine, 1969), our

33 understanding of disease in marine organisms remains quite limited, with a few notable

34 studies that have guided contemporary work (Jolles et al., 2002; Lafferty, Porter \& Ford,

35 2004; Mydlarz, Jones \& Harvell, 2006; Sweet, Bulling \& Cerrano, 2015).

36 A recent and dramatic pandemic known as "sea star wasting disease" (SSWD) has led to

37 very high mortality in a large number of sea star species on the Pacific coast of North

38 America (Hewson et al., 2014; Eisenlord et al., 2016; Menge et al., 2016; Montecino-Latorre

39 et al., 2016). By eliminating many predators from these coastal ecosystems, SSWD provides

40 novel opportunities to evaluate hypotheses of how species can drive community

41 composition (Menge et al., 2016; Gravem \& Morgan, 2017) as well as further exploration of

42 the pathogen or pathogens that may be driving these changes (Hewson et al., 2014). A

43 component of understanding how marine communities will respond to disease in general

44 involves exploration of host diversity for traits that influence susceptibility or mortality

45 (Vollmer \& Kline, 2008; Wright et al., 2017). Often there are evolutionary trade-offs that 
46 influence host diversity that are dependent on the prevalence of particular pathogens

47 (Aidoo et al., 2002; Gemmell \& Slate, 2006).

48 The sea star Pisaster ochraceus --- best known as a "keystone predator" that modifies the 49 diversity of its intertidal community (Paine, 1969) --- harbors a mutation in the elongation 50 factor 1- $\alpha$ (EF1A, hereafter) gene that is characterized as 'overdominant' (Pankey \& Wares, 51 2009); that is, where heterozygous individuals (carrying one copy of this mutation) have

52 dramatically higher fitness than either homozygote. At the time, with no apparent 53 mechanism for this heterozygote advantage, Pankey and Wares (2009) noted that 54 overdominance has often been associated with disease tolerance (Gemmell \& Slate, 2006).

55 Recent field surveys of apparently healthy and diseased individuals of P. ochraceus 56 suggested that individuals carrying the insertion mutation (ins) described by Pankey and 57 Wares (2009) have lower prevalence of (or mortality from) SSWD than individuals 58 homozygous for the wild-type (wild) sequence (Wares \& Schiebelhut, 2016).

59 The EF1A gene produces a "housekeeping" protein that is involved in translational 60 elongation (forming peptide bonds between amino acids) of newly-generated proteins.

61 However, EF1A also appears to be involved in diverse cellular functions (Ejiri, 2002), and 62 diversity at this gene has been implicated in variation in fitness in other metazoans 63 (Stearns, 1993; Stearns \& Kaiser, 1993). Currently, the mechanism by which the ins 64 mutation --- which is within an intron between two coding subunits (Pankey \& Wares, 65 2009) --- affects the function of EF1A or the cellular functions associated with SSWD 66 (Hewson et al., 2014) remains unknown, and of course the ins marker may simply be linked 67 to another polymorphism that is actually promoting these effects. However, the 
68 "moonlighting" functions of EF1A (Ejiri, 2002) include mediating responses to viral

69 infection (Li et al., 2013; Wei et al., 2014) and inflammation (Schulz et al., 2014), as well as

70 environmental stress (Bukovnic et al., 2009). It is not unusual for stress to be cited as a

71 component of disease susceptibility (Cohen et al., 2012). Current evidence is mixed about

72 what environmental stressors have promoted SSWD in P. ochraceus, with some studies

73 suggesting that elevated water temperature (Bates, Hilton \& Harley, 2009; Eisenlord et al.,

74 2016) influenced the outbreak in one region (the Salish Sea) and another study on the

75 Oregon coast indicating the opposite, that cooler water from upwelling may have been a

76 physiological stressor (Menge et al., 2016).

77 We can now query distinct genotypes for variation in RNA transcription to identify

78 components of cellular and molecular networks that are associated with specific trait

79 variation (Cohen et al., 2010). Here we test two hypotheses using RNA sequencing of a set

80 of individuals of each EF1A genotype in P. ochraceus (the mutation is homozygous lethal, so

81 there are only 2 genotypes for this marker). First, the mutation (or linked diversity) could

82 influence the overall regulation of other genes, in which case we may detect significantly

83 different expression of a set of loci between ins heterozygotes and wild homozygotes.

84 Second, we evaluate how individuals of each genotype respond to thermal stress, as the

85 effects of many mutations will be environment-dependent (Rutter et al., 2017).

86 Temperature shifts are associated with changes in feeding (Sanford, 1999), metabolism

87 (Fly et al., 2012), and intertidal distribution (Menge et al., 2016) in P. ochraceus. Thus, we

88 coupled a temperature challenge trial with behavioral observations and repeated RNA

89 sequencing to understand how individuals respond to periods of elevated temperature or

90 stress. In this case, we hypothesized that an interaction between environmental stress and 
91 cellular physiology could be indicated by distinct patterns of activity levels or changes in

92 expression across the two ins genotypes.

93 Our goal is to illuminate mechanisms by which EF1A ins heterozygotes in P. ochraceus may

94 be protected from SSWD, as this information may guide exploration of why some sea stars

95 in the Pacific intertidal community are more susceptible than others to this disease.

96 Additionally, this system provides an opportunity to explore how variation in expression of

97 a gene or gene network that is of fundamental importance to organismal development,

98 growth, and acclimation can affect the tolerance of an organism to disease.

99 Methods

100 Field and Lab

101 Individual P. ochraceus were collected from $\sim 0 \mathrm{~m}$ tidal depth within the Friday Harbor

102 Laboratories marine reserve (Friday Harbor, WA, $48.54^{\circ} \mathrm{N} 123.01^{\circ} \mathrm{W}$ ) in June 2016.

103 Collections were made following written permission from the Associate Director of the

104 Friday Harbor Laboratories. Individuals were placed in sea tables with ambient

105 temperature, unfiltered, running sea water within 1 hour of collection and fed available

106 bivalves ad libitum. After the experiment, all surviving individuals were returned to the 107 field.

108 At the beginning of the experiment two samples $(\sim 25 \mathrm{mg})$ of tube feet were removed from

109 each individual; one sample was placed in 95\% undenatured ethanol (for genotyping as in

110 Wares \& Schiebelhut, 2016), the other sample into RNALater (Thermo Fisher). Tissue

111 sampling was repeated following the heat trial described below. Distal tube feet were used 
112 in part to minimize damage to individual P. ochraceus, and to standardize contrasts of

113 regulatory change (Montgomery \& Mank, 2016). Individuals were kept in flow-through sea

114 tables in Vexar enclosures to ensure consistent individual identification. DNA samples were

115 tested for presence of SSaDV (the putative pathogen causing SSWD) using qPCR as in

116 Hewson et al. (2014).

117 Righting responses (Figure 1) were used to explore the physiological status of individuals

118 of each genotype subjected to periods of elevated temperature. Increasing the temperature

119 by $\sim 3^{\circ}$ is known to influence the physiology of P. ochraceus (Sanford, 1999; Fly et al.,

120 2012). Flow-through temperature treatments were performed as in Eisenlord et al (2016);

121 individuals were maintained at $+3^{\circ} \mathrm{C}$ for 8 days. Sea table temperature was monitored $4 \mathrm{x}$

122 daily with digital thermometers and with Hobo Tidbit data loggers. Righting response trials

123 were performed as in Held and Harley (2009). We recorded the time each individual

124 required to flip from the aboral side to the point that the majority of arms contacted the

125 surface on their oral side. Trials were performed three times in each condition: in ambient

126 seawater, at the end of the temperature trial, and again when individuals returned to

127 ambient temperature. Individuals that did not right themselves within 1 hour were

128 considered unresponsive and were excluded from subsequent analyses. Minimum and

129 mean righting response times were recorded; these values are examined across EF1A

130 genotypes using a t-test as well as a linear mixed-effects model evaluating response to

131 temperature by genotype using the ImerTest package (Kuznetsova, Bruun Brockhoff \&

132 Haubo Bojesen Christensen, 2016) in R version 3.3.2 (R Core Team, 2016). 


\section{RNA Sequencing and Comparison}

134 Samples of tube feet stored in RNALater were thawed on ice and $25 \mathrm{mg}$ were removed for

135 RNA isolation using a Qiagen RNEasy Mini-prep kit. A Qiagen TissueRuptor with sterile

136 disposable pestles was used for homogenization of each sample. RNA samples were

137 submitted to the Georgia Genomics Facility (GGF; dna.uga.edu) for stranded RNA library

138 preparation (Illumina TruSeq LT) and subsequent quality checks using an Agilent 2100

139 BioAnalyzer. Libraries were sequenced in parallel (high output PE75) on an Illumina

140 NextSeq 500 at GGF and then informatically demultiplexed.

141 Our pipeline followed Kelly et al. (2017), both with and without the utilization of $c d$-hit (Li

$142 \&$ Godzik, 2006) to reduce the sequence complexity in the data, using a sequence similarity

143 threshold of 98\%. Illumina adapter sequences were removed during the demultiplex step.

144 FASTQ data were cleaned using Trimmomatic (Bolger, Lohse \& Usadel, 2014) (default

145 settings), and 2 transcriptome assemblies were generated using in silico read normalization

146 in Trinity (Grabherr et al., 2011). The first assembly utilized data from all 20 RNA libraries;

147 the second utilized only the data from 4 individuals, 2 of each genotype, chosen for high

148 RIN values and read numbers. Trinity de novo assembly was performed on a Georgia

149 Advanced Computing Resource Center 512GB node with 8 processors. Individual RNA

150 libraries were then aligned to the assemblies using Bowtie2 (Langmead \& Salzberg, 2012)

151 and the RSEM method (Li \& Dewey, 2011) as in Haas et al. (2013).

152 All assembled Trinity clusters were used as blastx queries against the $n r$ database,

153 restricted to GI numbers for Echinodermata, with the best hit for each (e-value $<10^{-6}$ )

154 retained. A custom R script was used to collapse the expression count files by inferred gene 
155 and by BLAST homologies except where otherwise noted. Differential expression was

156 quantified using edgeR (McCarthy, Chen \& Smyth, 2012), filtering reads for a counts-per-

157 million $(\mathrm{CPM})>1$ in at least 2 of the libraries. Other filtering combinations were attempted

158 with similar results (V. K. Chandler, results not shown). Both negative binomial and

159 empirical Bayes dispersion measures were estimated before testing for differences. The

160 libraries representing ambient and elevated temperature exposure were evaluated

161 individually by genotype for differential expression between treatments, as well as a paired

162 sample analysis using edgeR.

163 Additionally, a sorted and unsorted permutation test of genotype contrasts was performed

164 to ensure that the EF1A genotype explained the greatest pattern of differentiation among

165 these samples. The sorted permutation test evaluated the number of differentially

166 expressed genes between the two genotype classes against a distribution generated from

167 (a) moving one library at a time into the other classification, (b) all permutations in which

168 one from each classification is moved to the other, and (c) where two libraries from each

169 classification are moved to the other. These were repeated for all such possible

170 permutations. The unsorted permutation test randomly drew libraries without

171 replacement to comprise two classes of equal size and repeated the contrast between

172 actual number of differentially expressed genes and the permutational distribution of this 173 value.

174 To specifically consider differential expression of EF1A, we considered all fragments that 175 successfully BLAST to NCBI accession AB070232, a 5kb sequence of the EF1A gene region

176 from the confamilial Asterias amurensis (Wada et al., 2002), and also used sequence data 
177 (NCBI KY489762-KY489768) generated from cloning of P. ochraceus EF1A (Pankey \&

178 Wares, 2009) to identify any expression of the focal intron region that harbors the ins

179 mutation. These latter assemblies were performed using Geneious R10 (Biomatters).

180 


\section{Results}

182 A total of 24 individuals were collected from the Friday Harbor Laboratories marine

183 reserve, 1 was returned due to injury, and 20 survived our lab trials (one individual, an ins

184 heterozygote, died of apparent SSWD; 2 others from distinct external infections) and were

185 returned to their original location. As in previous studies (Pankey \& Wares, 2009), the ratio

186 of heterozygotes $(+/$ ins, or ins $)$ to homozygotes $(+/+$ or wild $)$ at the EF1A locus was $\sim 1: 1$. In

187 order of initial labeling, the first 5 individuals of each genotype that had complete

188 behavioral data were selected for RNA sequencing (Supplemental Information). Each

189 individual was genotyped 3 times from 3 separate tissue samples with no errors. These 10

190 individuals exhibited no visible signs of SSWD and tested negative for SSaDV.

\section{Behavior}

192 For the 10 individuals analyzed in full, righting response trials (Figure 1) suggested that ins

193 heterozygotes righted themselves approximately 1.8 times faster than wild homozygotes

194 (Supplemental S1; t-test $\mathrm{p}=0.01$; linear model $\mathrm{p}=0.022$ ) at both temperatures. However,

195 including all data on righting response (from all 17 individuals with complete behavior

196 data; $n=6$ unresponsive individuals were evenly distributed across genotypes) introduces

197 higher variation in response by genotype; the effect is in the same direction but not

198 significant ( $\mathrm{t}$-test $\mathrm{p}=0.77$; linear model $\mathrm{p}=0.737)$. Including wild individual "Po5" in the

199 ins genotypic class (see below for rationale) strengthens these results but they are still not

200 statistically significant when all individuals are included. 
201 Sequenced RNA Diversity

202 Supplemental Information S1 provides information for each library used in transcriptome 203 assemblies; all sequence data are available from NCBI (BioProject PRJNA357374). Of the 204 two de novo assemblies, the reduced-input transcriptome had greater length and quality of 205 contigs ( $\mathrm{N}_{50}$ of $1799 \mathrm{bp}$, median contig length 513 , total assembled bases $\left.179,034,265\right)$ and 206 is the focus of subsequent analyses. Fragments that were differentially expressed (False 207 Discovery Rate $($ FDR $)<0.01)$ between the two genotypes from the two Trinity assemblies 208 were themselves de novo aligned in Geneious R10; 80.76\% of contigs from one of the two 209 assemblies aligned with one from the other. Using a 98\% threshold with $c d$-hit reduced the 210 total number of sequences from 179563 to 154150 . All results are qualitatively similar

211 across all three assemblies, but the results reported hereafter are based on the $c d$-hit 212 reduced assembly.

213 The total of 154150 transcripts analyzed represented 62713 Trinity clusters and 110525

214 gene regions after isoforms were summed for each. Additionally, expression counts were 215 summed for fragments with identical NCBI gi numbers, reducing the total number of 216 expressed fragments to 107189. A total of 9953 distinct gi values were recovered from

217 blastx (e-value $<10^{-6} ; 9563$ of these were hits to Strongylocentrotus purpuratus).

218 Supplemental Table S1 shows information for all fragments that passed our CPM filters.

220 Permutational Testing

221 For each iteration of the sorted permutation test, the number of gene fragments that are

222 significantly different (FDR $<0.01)$ was identified and contrasted with the true

223 classification. The results suggest that differentiation of the two genotypes is robust 
224 relative to the most extreme misassignments (Figure 2), and greater than 0.96 of all

225 permutations. All permutations with higher counts of differentially expressed transcripts

226 involve re-assignment of individual Po5 (wild); though EF1A genotype was confirmed for

227 this individual, it is similar to the ins heterozygotes for many expression traits

228 (Supplemental S1). Full unsorted permutation testing with 500 permutations also showed

229 that the effect size using EF1A genotypes as a means of partitioning the data is large

230 relative to random (96.8th percentile). If library Po5 is excluded, the expression differences

231 between genotype classes is greater than any permuted re-sampling of the data.

\section{Comparison of differential expression across genotypes}

233 There are strong differences in the constitutive expression patterns of the 5 wild and 5 ins

234 individuals assayed. There are 178 fragments exhibiting differential expression with FDR <

235 0.01, and 18 with FDR $<0.0001$ (Figure 3). As above, if library Po5 is excluded, a greater

236 number $(\mathrm{n}=395)$ of fragments exhibit differential expression (FDR $<0.01)$, suggesting that

237 this individual represents an inconsistent expression phenotype for its EF1A genotype (see

238 heatmaps in Supplemental Table S1). If library Po5 is instead categorized as an ins

239 heterozygote, there are 447 distinct transcripts between the two genotypes (FDR $<0.01$ ).

240 The full paired analysis (using all 10 libraries from both temperature treatments) identifies

241 a similar number of DE loci overall, and a similar differentiation is identified between

242 genotypes at elevated temperatures.

243 The effect of the ins genotype appears to be inhibitory; Figure 3A shows only those

244 fragments that are differentially expressed between the two genotypes, and only 25 of 178

245 fragments with FDR $<0.01$ exhibit higher expression in heterozygotes. Many of the

246 significantly elevated transcripts in heterozygotes are modestly expressed compared to the 
247 significantly elevated transcripts from wild homozygotes. The average log CPM for

248 fragments with FDR $<0.01$ that are more highly expressed in ins heterozygotes is 0.876

249 (maximum 6.154), while the same average for fragments that are more highly expressed in 250 wild homozygotes is 3.639 (maximum 11.217). A similar, but stronger, result is obtained

251 when Po5 is excluded, with only 45 of 395 differentially expressed (FDR $<0.01$ ) fragments

252 being more highly expressed in heterozygotes (Figure 3B); for differential expression at the

253 level of FDR $<10^{-4}$, only 6 of 131 fragments are more highly expressed in ins heterozygotes.

\section{Response to elevated water temperature}

256 Following exposure to water warmed by $+3^{\circ} \mathrm{C}$, wild homozygotes exhibited a larger number

257 of potential loci $(\mathrm{n}=46)$ that changed in expression (FDR $<0.01)$ than ins heterozygotes

258 ( $\mathrm{n}=6$; see Supplemental Information). Using a more inclusive cutoff (FDR $<0.1$, as in Wright

259 et al., 2017) amplifies this contrast, with wild homozygotes showing differential expression

260 at 197 regions and heterozygotes at only 14 gene regions. If individual Po5 is excluded, the

261 remaining wild homozygotes then exhibit 62 fragments that change in expression (FDR <

$2620.01 ; 190$ with FDR $<0.1$ ), suggesting again that the expression phenotype of this

263 individual adds considerable variance to the expression patterns of homozygotes.

264 Additionally, the average effect of temperature exposure appears to be in opposite

265 directions: while ins individuals have a mean log fold change in expression across loci of

$2660.278+/-2.132$, wild homozygotes have a mean reduced expression across loci (log fold

267 change $=-0.455+/-1.685)$. Of all fragments identified as responding to the temperature

268 treatment, 3 of 6 identified in the heterozygotes are also found among those that are

269 differentially expressed in the homozygotes (whether or not Po5 is included, at FDR < 
270 0.01). These results are suggestive that homozygous individuals experienced a greater net

271 change in expression phenotype following exposure to heat than ins heterozygotes (Figure $2724)$.

273

274 Elongation factor 1-alpha

275 Following BLAST analysis, only 1 fragment sufficiently matched NCBI accession AB070232

276 (Wada et al., 2002), a $5 \mathrm{~kb}$ sequence of EF1A from Asterias amurensis. This fragment does

277 not appear to be differentially expressed (FDR $<0.01$ ) between wild and ins EF1A

278 genotypes. Including other fragments that have sufficient homology to "elongation factor 1-

$279 \alpha^{\prime \prime}$ (a partial fragment from Patiria miniata) provides similar results, whether or not

280 individual Po5 is included. Previous analyses that assessed BLAST homology using the

281 blastn algorithm against $A$. amurensis also showed that summing across all putative EF1A

282 homologs indicated no significant expression differences at this locus

283 (DOI:10.7287/peerj.preprints.2990v1). Assembly of RNA sequence fragments from

284 libraries of the two genotypes to the full A. amurensis EF1A sequence showed no obvious

285 distinctions in coverage of coding regions (results not shown). 


\section{Discussion}

288 The data and results presented here lead to a remarkable conclusion --- that the canonical

289 intertidal predator, Pisaster ochraceus, after decades of intensive ecological scrutiny,

290 appears to include two physiologically distinct types. We know that these types are not

291 reproductively isolated (Pankey \& Wares, 2009), so these distinct types are formed each

292 generation via an overdominant polymorphism that influences regulation of gene

293 expression. The two forms significantly (FDR < 0.01) differ at $0.404 \%$ of all expressed

294 fragments analyzed here, a small but important proportion (Figures 2,3). These data are

295 consistent with a mutation in a regulatory region in that ins heterozygotes have a limited 296 expression of many of the differentially expressed loci relative to wild individuals (Figure

297 3). Perhaps more importantly, the two forms responded very distinctly to temperature

298 stress (Figure 4), with a qualitatively distinct expression change profile for wild

299 homozygotes than ins heterozygotes. The results from one unusual individual (Po5) clearly 300 suggest, however, that the ins genotype marker used to separate these groups may not be

301 the causal mutation for these cellular and physiological shifts. Pankey \& Wares (2009) had

302 discussed linked polymorphic diversity using cloned and sequenced fragments of the EF1A

303 intron that carries the mutation, but expressed concerns about PCR-mediated

304 recombination in those data. It now seems likely that Po5 harbored a recombination event,

305 appearing to be wild but with the expression profile of an ins individual. Future work will

306 explore this region in greater detail.

307 Intriguingly, there is now a linkage between these physiological changes that seem to

308 reduce the individual response to temperature stress and the ins marker that is associated

309 with reduced incidence or mortality to SSWD (Wares \& Schiebelhut, 2016). Harvell et al. 
310 (2002) noted that a warming climate could affect the development or survival of

311 pathogens, but certainly could also interact with host physiological stress as well (Cohen et

312 al., 2012). Our study is limited in understanding this linkage in several ways - there has

313 been little or no experimental annotation of differentially expressed genes in P. ochraceus,

314 and our temperature contrast experiment did not include control replicates to assess the

315 effect of stress from being held in our mesocosms with or without temperature

316 manipulation. Nevertheless the effect of our temperature stress trial suggests heritable

317 variation in how individuals respond to heat stress. As elevated temperatures may

318 accelerate SSWD (Bates, Hilton \& Harley, 2009; Eisenlord et al., 2016; but see Menge et al.,

319 2016), the likelihood that the mutation linked to the ins marker ameliorates multiple forms

320 of stressors on the health of an individual is worth further investigation.

321 As P. ochraceus is likely to vary behavior along with physiological stress (Monaco et al.,

322 2015), we also evaluated whether there was an interaction between the EF1A genotype,

323 temperature stress, and behavioral activity. Righting responses were used to understand

324 the response to heat as an influence on activity levels (Held \& Harley, 2009). Heterozygous

325 individuals tend to right themselves more quickly in a limited sample. However, individual-

326 level variation was high and the biological effect of genotype on this response may be low

327 or absent. Individuals appeared to be consistent in their response, i.e. individuals with long

328 response times tended to do so at all treatments; whether this is associated in any way with

329 effects of this genotype requires further consideration. Overall, we conclude that righting

330 response is a noisy response variable and perhaps ineffective for assaying physiological

331 contrasts. We are not the first to recognize this difficulty: 
332

333

334

335

336

338

339

340

341

342

343

344

345

346

347

348

350

351

352

353

354

"It could probably be said, in a word, that the starfish may, and does, in different cases, right itself in any conceivable way, - and indeed, in many ways that would not readily be conceived before they were observed." -Jennings (1907)

Thus, other approaches such as respirometry (Fly et al., 2012) are needed to more directly understand the genetic basis of stress response in P. ochraceus.

It is also notable that the regulatory effect of the ins mutation (or a linked polymorphism) has a consistent response - there is a clear asymmetry (Figure 3) in expression of transcripts suggesting that the ins mutation affects a promoter region. The genomic features that are differentially expressed in response to the ins mutation are of interest, but accurate functional annotation of these transcripts are currently limited by the tremendous evolutionary divergence between Pisaster and other characterized Asteroid genomes (Patiria miniata (echinobase.org) and Acanthaster planci (Hall et al., 2017)). Generating a more extensive list of loci that are coregulated by the ins marker is of modest utility without better experimental data in this non-model organism (Hudson, Dalrymple \& Reverter, 2012). We do not know if the differentially expressed loci are relatively rapidly evolving, or if these transcripts represent noncoding RNA; currently, these hypotheses are difficult to test with available resources (Dinger et al., 2008). Our ability to explore the effects of differential genotype in $P$. ochraceus may also require an understanding of tissue specificity. Here, tube feet were used as simple non-invasive tissues for sampling because the health of the local population is of concern. Future efforts could target tissues more specific to immune response function. For example, EF1A is already thought to regulate interleukins (Schulz et al., 2014), which are represented among the identifiable differentially expressed gene regions in this study (Supplement S1). These are thought to 
355 be produced in the axial organ and are a basic component of the echinoderm immune

356 response (Mydlarz, Jones \& Harvell, 2006; Leclerc \& Otten, 2013) that stimulate

357 coelomocytes and are associated with antiviral activity (Ghiasi et al., 2002).

358 A polymorphism like this should not be stable unless there is some balance of benefits to

359 both genotypes (Subramaniam \& Rausher, 2000). With typical genotype frequencies in the

360 wild (Pankey \& Wares, 2009,Wares \& Schiebelhut, 2016), approximately 1/16th of all

361 offspring ( $1 / 4$ of the offspring from $1 / 4$ of the random mating events) are lost each

362 generation to this polymorphism. Similar levels of reduced fitness are involved in

363 explorations of Dobzhansky-Muller interactions associated with outbreeding depression

364 (Sweigart, Fishman \& Willis, 2006). This is a considerable mutational load attributed to a

365 single polymorphism yet the sudden appearance, or incidence in recent decades, of high

366 mortality events like SSWD is unlikely to be a sufficient mechanism for maintaining this

367 polymorphism. The two allelic classes each harbor considerable levels of flanking diversity

368 and appear to be relatively divergent and ancient (Pankey \& Wares, 2009), and the high

369 frequency of the ins allele throughout the range of P. ochraceus (Pankey \& Wares, 2009;

370 Wares \& Schiebelhut, 2016) suggests its origin is not recent (Slatkin \& Rannala, 2000).

371 The question remains, what has maintained this polymorphism, and what can we learn

372 from this about disease in other echinoderms - or more broadly, other animals - about

373 interactions of stress and pathogens? In other major epidemics, it has been noted that

374 mortality has been highest in individuals that are weak or that have the strongest

375 inflammatory/immune response to a pathogen (Lai, Ng \& Cheng, 2015). If this is true,

376 perhaps wild individuals are more prone to extreme stress responses. The reality is that 
377 stress tolerance is thought to be highly context-dependent (Berry et al., 2011; Bay \&

378 Palumbi, 2015) and may be difficult to assess in a wild population such as the Pisaster

379 surveyed here. Each individual bears high levels of additional variation that mediates their

380 responses to environment, pathogens, and so on. The fact that the ins mutation is

381 associated with such strong biological effect amidst the noise of other natural genomic

382 diversity is extraordinary. Certainly there are other examples of single mutations that

383 confer significant health and life history consequences on carriers (Aidoo et al., 2002;

384 Drnevich et al., 2004; Gemmell \& Slate, 2006). Distinct phenotype classes within a species

385 often have distinct expression profiles (McDonald et al., 1977; Garg et al., 2016), including

386 instances of disease or tolerance phenotypes (Emilsson et al., 2008; O'Connor et al., 2017).

387 Our hopes are that further exploration of this system, in an ecologically important sea star

388 (Paine, 1969; Menge et al., 2016), will be of relevance for a more general understanding of

389 health and pathogen tolerance.

\section{Acknowledgments}

391 We thank M. Kelly, J. Griffiths, A. Del Rio, M. Bitter, K. Coombs, J. Wong, J. Wallace, M. Mintz, 392 and R. Wares for field and lab efforts that contributed to this work at Friday Harbor 393 Laboratories (FHL). Additionally, support from M. Eisenlord, B. Swalla, M. Dethier, S.

394 George, J. Hodin, and the staff at FHL was invaluable. Technical input from D. Barshis, S.

395 Caplins, K. Bockrath, M. MacManes, K. Thornton, and S. Pankey was greatly appreciated.

396 Computational support, particularly D. Brown, Y. Huang, R. Masalia, and A. Bewick along

397 with lab support by R. Nilsen, was greatly appreciated. Ideas generated in discussion with

398 S. Gravem, L. Schiebelhut, and M. Dawson helped develop this project. S. Pankey, S. Heisel, J. 
399 Hamlin, I. Hewson, K. Bockrath, E. Sotka, F. Barreto, and C. Ewers-Saucedo evaluated early

400 drafts of the manuscript; E. Sotka, M. Dawson, S. Pankey, and M. Kelly helped with later

401 versions along with M. Lloyd and one anonymous reviewer.

402 In Memoriam

403 Virginia Katelyn Chandler unexpectedly passed away in June 2017 after submission of the

404 first version of this manuscript; her contributions to this project, in just her first 2 years at

405 The University of Georgia, were outstanding. Deepest condolences to her family and

406 friends, from all in the Wares Lab and at the University of Georgia.

407 


\section{Literature Cited}

409

410 Aidoo M., Terlouw DJ., Kolczak M., McElroy PD., Kuile FO ter., Kariuki S., Nahlen BL., Lal AA.,

411 Udhayakumar V. 2002. Protective effects of the sickle cell gene against malaria morbidity

412 and mortality. Lancet 359:1311-1312. DOI: Doi 10.1016/S0140-6736(02)08273-9.

413 Bates AE., Hilton BJ., Harley CDG. 2009. Effects of temperature, season and locality on

414 wasting disease in the keystone predatory sea star Pisaster ochraceus. Diseases of Aquatic

415 Organisms 86:245-251. DOI: 10.3354/dao02125.

416 Bay RA., Palumbi SR. 2015. Rapid acclimation ability mediated by transcriptome changes in

417 reef-building corals. Genome Biology and Evolution 7:1602-1612. DOI:

418 10.1093/gbe/evv085.

419 Berry DB., Guan QN., Hose J., Haroon S., Gebbia M., Heisler LE., Nislow C., Giaever G., Gasch

420 AP. 2011. Multiple means to the same end: The genetic basis of acquired stress resistance

421 in yeast. Plos Genetics 7. DOI: ARTN e1002353 10.1371/journal.pgen.1002353.

422 Bolger AM., Lohse M., Usadel B. 2014. Trimmomatic: A flexible trimmer for Illumina

423 sequence data. Bioinformatics 30:2114-2120. DOI: 10.1093/bioinformatics/btu170.

424 Bruno JF., Stachowicz JJ., Bertness MD. 2003. Inclusion of facilitation into ecological theory.

425 Trends in Ecology and Evolution 18:119-125. DOI: 10.1016/S0169-5347(02)00045-9.

426 Bukovnic U., Fu J., Bennett M., Prasad P., Ristic Z. 2009. Heat tolerance and expression of

427 protein synthesis elongation factors, EF-Tu and EF- $1 \alpha$, in spring wheat. Functional Plant

428 Biology 36:234-241. 
429 Cohen D., Bogeat-Triboulot MB., Tisserant E., Balzergue S., Martin-Magniette ML., Lelandais

430 G., Ningre N., Renou JP., Tamby JP., Le Thiec D., Hummel I. 2010. Comparative

431 transcriptomics of drought responses in Populus: A meta-analysis of genome-wide

432 expression profiling in mature leaves and root apices across two genotypes. BMC Genomics

433 11:630. DOI: 10.1186/1471-2164-11-630.

434 Cohen S., Janicki-Deverts D., Doyle WJ., Miller GE., Frank E., Rabin BS., Turner RB. 2012.

435 Chronic stress, glucocorticoid receptor resistance, inflammation, and disease risk.

436 Proceedings of the National Academy of Sciences of the United States of America 109:5995-

437 5999. DOI: 10.1073/pnas.1118355109.

438 Connell JH. 1961. The influence of interspecific competition and other factors on the

439 distribution of the barnacle Chthamalus stellatus. Ecology 42:710-723.

440 Dinger ME., Pang KC., Mercer TR., Mattick JS. 2008. Differentiating protein-coding and

441 noncoding RNA: Challenges and ambiguities. Plos Computational Biology 4. DOI: ARTN

442 e1000176 10.1371/journal.pcbi.1000176.

443 Drnevich JM., Reedy MM., Ruedi EA., Rodriguez-Zas S., Hughes KA. 2004. Quantitative

444 evolutionary genomics: Differential gene expression and male reproductive success in

445 Drosophila melanogaster. Proc Biol Sci 271:2267-73. DOI: 10.1098/rspb.2004.2880.

446 Duffy JE., Hay ME. 2001. The ecology and evolution of marine consumer-prey interactions.

447 In: Bertness MD, Gaines SD, Hay ME eds. Marine community ecology. Sunderland, MA:

448 Sinauer, 131-158. 
449 Eisenlord ME., Groner ML., Yoshioka RM., Elliott J., Maynard J., Fradkin S., Turner M., Pyne

450 K., Rivlin N., Hooidonk R van., Harvell CD. 2016. Ochre star mortality during the 2014

451 wasting disease epizootic: Role of population size structure and temperature. Phil. Trans. B

452 371:20150212. DOI: 10.1098/rstb.2015.0212.

453 Ejiri S. 2002. Moonlighting functions of polypeptide elongation factor 1: From actin

454 bundling to zinc finger protein r1-associated nuclear localization. Biosci. Biotechnol.

455 Biochem. 66:1-21.

456 Emilsson V., Thorleifsson G., Zhang B., Leonardson AS., Zink F., Zhu J., Carlson S., Helgason

457 A., Walters GB., Gunnarsdottir S., Mouy M., Steinthorsdottir V., Eiriksdottir GH., Bjornsdottir

458 G., Reynisdottir I., Gudbjartsson D., Helgadottir A., Jonasdottir A., Jonasdottir A.,

459 Styrkarsdottir U., Gretarsdottir S., Magnusson KP., Stefansson H., Fossdal R., Kristjansson K.,

460 Gislason HG., Stefansson T., Leifsson BG., Thorsteinsdottir U., Lamb JR., Gulcher JR., Reitman

461 ML., Kong A., Schadt EE., Stefansson K. 2008. Genetics of gene expression and its effect on

462 disease. Nature 452:423-U2. DOI: 10.1038/nature06758.

463 Fly EK., Monaco CJ., Pincebourde S., Tullis A. 2012. The influence of intertidal location and

464 temperature on the metabolic cost of emersion in Pisaster ochraceus. Journal of

465 Experimental Marine Biology and Ecology 422:20-28. DOI: 10.1016/j.jembe.2012.04.007.

466 Garg R., Shankar R., Thakkar B., Kudapa H., Krishnamurthy L., Mantri N., Varshney RK.,

467 Bhatia S., Jain M. 2016. Transcriptome analyses reveal genotype- and developmental stage-

468 specific molecular responses to drought and salinity stresses in chickpea. Scientific Reports

469 6. DOI: Artn 19228 10.1038/Srep19228. 
470 Gemmell NJ., Slate J. 2006. Heterozygote advantage for fecundity. PLos One 1:e125. DOI:

471 10.1371/journal.pone.0000125.

472 Ghiasi H., Osorio Y., Perng GC., Nesburn AB., Wechsler SL. 2002. Overexpression of

473 interleukin-2 by a recombinant herpes simplex virus type 1 attenuates pathogenicity and

474 enhances antiviral immunity. Journal of Virology 76:9069-9078. DOI:

475 10.1128/JVI.76.18.9069-9078.2002.

476 Grabherr MG., Haas BJ., Yassour M., Levin JZ., Thompson DA., Amit I., Adiconis X., Fan L.,

477 Raychowdhury R., Zeng QD., Chen ZH., Mauceli E., Hacohen N., Gnirke A., Rhind N., Palma F

478 di., Birren BW., Nusbaum C., Lindblad-Toh K., Friedman N., Regev A. 2011. Full-length

479 transcriptome assembly from RNA-seq data without a reference genome. Nature

480 Biotechnology 29:644-U130. DOI: 10.1038/nbt.1883.

481 Gravem SA., Morgan SG. 2017. Shifts in intertidal zonation and refuge use by prey after

482 mass mortalities of two predators. Ecology 98:1006-1015. DOI:

483 10.1002/ecy.1672/suppinfo.

484 Haas BJ., Papanicolaou A., Yassour M., Grabherr M., Blood PD., Bowden J., Couger MB., Eccles

485 D., Li B., Lieber M., MacManes MD., Ott M., Orvis J., Pochet N., Strozzi F., Weeks N.,

486 Westerman R., William T., Dewey CN., Henschel R., Leduc RD., Friedman N., Regev A. 2013.

487 De novo transcript sequence reconstruction from RNA-seq using the Trinity platform for

488 reference generation and analysis. Nature Protocols 8:1494-1512. DOI:

489 10.1038/nprot.2013.084. 
490 Hall MR., Kocot KM., Baughman KW., Fernandez-Valverde SL., Gauthier MEA., Hatleberg 491 WL., Krishnan A., McDougall C., Motti CA., Shoguchi E., Wang T., Xiang X., Zhao M., Bose U., 492 Shinzato C., Hisata K., Fujie M., Kanda M., Cummins SF., Satoh N., Degnan SM., Degnan BM. 493 2017. The crown-of-thorns starfish genome as a guide for biocontrol of this coral reef pest. 494 Nature 544:231-234.

495 Harvell CD., Mitchell CE., Ward JR., Altizer S., Dobson AP., Ostfeld RS., Samuel MD. 2002. 496 Climate warming and disease risks for terrestrial and marine biota. Science 296:21584972162.

498 Held MBE., Harley CDG. 2009. Responses to low salinity by the sea star Pisaster ochraceus 499 from high- and low-salinity populations. Invertebrate Biology 128:381-390. DOI: 500 10.1111/j.1744-7410.2009.00175.x.

501 Hewson I., Button JB., Gudenkauf BM., Miner B., Newton AL., Gaydos JK., Wynne J., Groves 502 CL., Hendler G., Murray M., Fradkin S., Breitbart M., Fahsbender E., Lafferty KD., Kilpatrick 503 AM., Miner CM., Raimondi P., Lahner L., Friedman CS., Daniels S., Haulena M., Marliave J., 504 Burge CA., Eisenlord ME., Harvell CD. 2014. Densovirus associated with sea-star wasting 505 disease and mass mortality. Proceedings of the National Academy of Sciences of the United 506 States of America 111:17278-17283. DOI: 10.1073/pnas.1416625111.

507 Hudson NJ., Dalrymple BP., Reverter A. 2012. Beyond differential expression: The quest for 508 causal mutations and effector molecules. BMC Genomics 13:356. DOI: 10.1186/1471-2164509 13-356. 
510 Jennings HS. 1907. Behavior of the starfish Asterias forreri de Loriol. University of California

511 Publications in Zoology 4:53-185.

512 Jolles AE., Sullivan P., Alker AP., Harvell CD. 2002. Disease transmission of Aspergillosis in

513 sea fans: Inferring process from spatial pattern. Ecology 83:2373-2378. DOI: Doi

$514 \quad 10.2307 / 3071798$.

515 Kelly MW., Pankey MS., DeBiasse MB., Plachetzki DC. 2017. Adaptation to heat stress

516 reduces phenotypic and transcriptional plasticity in a marine copepod. Functional Ecology

517 31:398-406. DOI: 10.1111/1365-2435.12725.

518 Kuznetsova A., Bruun Brockhoff P., Haubo Bojesen Christensen R. 2016. LmerTest: Tests in

519 linear mixed effects models.

520 Lafferty KD., Porter JW., Ford SE. 2004. Are diseases increasing in the ocean? Annual Review

521 of Ecology Evolution and Systematics 35:31-54. DOI:

522 10.1146/annurev.ecolsys.35.021103.105704.

523 Lai KY., Ng WYG., Cheng FF. 2015. The W-shaped mortality-age distribution of novel H1N1

524 influenza virus helps reconstruct the second wave of pandemic 1918 Spanish flu. J. Pulm.

525 Respir. Med. 5:2.

526 Langmead B., Salzberg SL. 2012. Fast gapped-read alignment with bowtie 2. Nature

527 Methods 9:357-U54. DOI: 10.1038/NMETH.1923.

528 Leclerc M., Otten P. 2013. Evidence of interleukin genes in the sea-star: Asterias rubens

529 (Echinodermata). Am. J. Immunology 9:65-67. 
530 Li B., Dewey CN. 2011. RSEM: Accurate transcript quantification from RNA-seq data with or

531 without a reference genome. Bmc Bioinformatics 12. DOI: Artn 323 10.1186/1471-2105-

$532 \quad 12-323$.

533 Li WZ., Godzik A. 2006. Cd-hit: A fast program for clustering and comparing large sets of 534 protein or nucleotide sequences. Bioinformatics 22:1658-1659. DOI:

535 10.1093/bioinformatics/btl158.

536 Li DS., Wei T., Abbott CM., Harrich D. 2013. The unexpected roles of eukaryotic translation 537 elongation factors in RNA virus replication and pathogenesis. Microbiology and Molecular 538 Biology Reviews 77:253-266. DOI: 10.1128/MMBR.00059-12.

539 LoGiudice K., Ostfeld RS., Schmidt KA., Keesing F. 2003. The ecology of infectious disease:

540 Effects of host diversity and community composition on lyme disease risk. Proceedings of 541 the National Academy of Sciences of the United States of America 100:567-571. DOI:

$54210.1073 /$ pnas.0233733100.

543 McCarthy DJ., Chen YS., Smyth GK. 2012. Differential expression analysis of multifactor

544 RNA-seq experiments with respect to biological variation. Nucleic Acids Research 40:4288545 4297. DOI: 10.1093/nar/gks042.

546 McDonald JF., Chambers GK., David J., Ayala FJ. 1977. Adaptive response due to changes in 547 gene regulation: A study with Drosophila. Proc Natl Acad Sci U S A 74:4562-6.

548 Menge BA., Cerny-Chipman EB., Johnson A., Sullivan J., Gravem S., Chan F. 2016. Sea star 549 wasting disease in the keystone predator Pisaster ochraceus in Oregon: Insights into 550 differential population impacts, recovery, predation rate, and temperature effects from 
551 long-term research (vol 11, e0153994, 2016). Plos One 11. DOI: ARTN e0157302

552 10.1371/journal.pone.0157302.

553 Mitchell CE., Power AG. 2006. Disease dynamics in plant communities. In: Collinge SK, Ray C 554 eds. Community structure and pathogen dynamics. Oxford: Oxford University Press, 58-72.

555 Monaco CJ., Wethey DS., Gulledge S., Helmuth B. 2015. Shore-level size gradients and 556 thermal refuge use in the predatory sea star Pisaster ochraceus: The role of environmental 557 stressors. Marine Ecology Progress Series 539:191-205.

558 Montecino-Latorre D., Eisenlord ME., Turner M., Yoshioka R., Harvell CD., Pattengill-

559 Semmens CV., Nichols JD., Gaydos JK. 2016. Devastating transboundary impacts of sea star

560 wasting disease on subtidal asteroids. Plos One 11. DOI: ARTN e0163190

561 10.1371/journal.pone.0163190.

562 Montgomery SH., Mank JE. 2016. Inferring regulatory change from gene expression: The

563 confounding effects of tissue scaling. Molecular Ecology 25:5114-5128. DOI:

564 10.1111/mec.13824.

565 Mydlarz L., Jones L., Harvell C. 2006. Innate immunity, environmental drivers, and disease

566 ecology of marine and freshwater invertebrates. Annu. Rev. Ecol. Evol. Syst. 37:251-288.

567 O'Connor LJ., Gusev A., Liu XH., Loh P-R., Finucane HK., Price A. 2017. Estimating the

568 proportion of disease heritability mediated by gene expression levels. bioRxiv. DOI:

569 doi.org/10.1101/118018.

570 Paine RT. 1969. A note on trophic complexity and community stability. American Naturalist 571 103:91-93. DOI: Doi 10.1086/282586. 
572 Pankey MS., Wares JP. 2009. Overdominant maintenance of diversity in seastar Pisaster

573 ochraceus. J. Evol. Biol. 22:80-87.

574 R Core Team. 2016. R: A language and environment for statistical computing. Vienna,

575 Austria: R Foundation for Statistical Computing.

576 Rutter MT., Wieckowski YM., Murren CJ., Strand AE. 2017. Fitness effects of mutation:

577 Testing genetic redundancy in Arabidopsis thaliana. Journal of Evolutionary Biology

578 30:1124-1135. DOI: 10.1111/jeb.13081.

579 Sanford E. 1999. Regulation of keystone predation by small changes in ocean temperature.

$580 \quad$ Science 283:2095-7.

581 Schulz I., Engel C., Niestroj AJ., Kehlen A., Rahfeld JU., Kleinschmidt M., Lehmann K., Rossner

582 S., Demuth HU. 2014. A non-canonical function of eukaryotic elongation factor $1 \alpha 1$ :

583 Regulation of interleukin-6 expression. Biochimica Et Biophysica Acta-Molecular Cell

584 Research 1843:965-975. DOI: 10.1016/j.bbamcr.2014.01.022.

585 Slatkin M., Rannala B. 2000. Estimating allele age. Annu. Rev. Genomics Hum. Genet. 1:225586249.

587 Stearns SC. 1993. Effects of fitness components of enhanced expression of elongation factor

588 EF-1 $\alpha$ in Drosophila melanogaster. I: The contrasting approaches of molecular and

589 population biologists. Am Nat 142:961-993.

590 Stearns SC., Kaiser M. 1993. The effects of enhanced expression of elongation factor EF-1 $\alpha$

591 on lifespan in Drosophila melanogaster. iv. a summary of three experiments. Genetica

592 91:167-182. 
593 Stephens PR., Altizer S., Smith KF., Aguirre AA., Brown JH., Budischak SA., Byers JE., Dallas

594 TA., Davies TJ., Drake JM., Ezenwa VO., Farrell MJ., Gittleman JL., Han BA., Huang S.,

595 Hutchinson RA., Johnson P., Nunn CL., Onstad D., Park A., Vazquez-Prokopec GM., Schmidt

596 JP., Poulin R. 2016. The macroecology of infectious diseases: A new perspective on global-

597 scale drivers of pathogen distributions and impacts. Ecology Letters 19:1159-1171. DOI:

598 10.1111/ele.12644.

599 Subramaniam B., Rausher MD. 2000. Balancing selection on a floral polymorphism.

600 Evolution 54:691-695.

601 Sweet M., Bulling M., Cerrano C. 2015. A novel sponge disease caused by a consortium of 602 micro-organisms. Coral Reefs 34:871-883. DOI: 10.1007/s00338-015-1284-0.

603 Sweigart AL., Fishman L., Willis JH. 2006. A simple genetic incompatibility causes hybrid 604 male sterility in Mimulus. Genetics 172:2465-2479. DOI: 10.1534/genetics.105.053686.

605 Vellend M. 2016. The theory of ecological communities. Princeton, NJ: Princeton University 606 Press.

607 Vollmer SV., Kline DI. 2008. Natural disease resistance in threatened staghorn corals. PLOS 608 One 3. DOI: ARTN e3718 10.1371/journal.pone.0003718.

609 Wada H., Kobayashi M., Sato R., Satoh N., Miyasaka H., Shirayama Y. 2002. Dynamic 610 insertion-deletion of introns in deuterostome EF-1 alpha genes. Journal of Molecular 611 Evolution 54:118-128. 
612 Wares JP., Schiebelhut LM. 2016. What doesn't kill them makes them stronger: An

613 association between elongation factor 1-alpha overdominance in the sea star Pisaster

614 ochraceus and "sea star wasting disease". PeerJ 4:e1876. D0I: 10.7717/peerj.1876.

615 Wei T., Li DS., Marcial D., Khan M., Lin MH., Snape N., Ghildyal R., Harrich D., Spann K. 2014.

616 The eukaryotic elongation factor $1 \mathrm{~A}$ is critical for genome replication of the Paramyxovirus

617 respiratory syncytial virus. Plos One 9. DOI: Artn E114447 10.1371/Journal.Pone.0114447.

618 Wright RM., Kenkel CD., Dunn CE., Shilling EN., Bay LK., Matz MV. 2017. Intraspecific

619 differences in molecular stress responses and coral pathobiome contribute to mortality

620 under bacterial challenge in Acropora millepora. Scientific Reports 7:2609. DOI:

621 DOI:10.1038/s41598-017-02685-1.

622

623

624 
625 Figure 1. Aboral view of Pisaster in righting response trial. Photo by JPW.

626

627 Figure 2. Sorted permutational misassignment of individuals and comparison

628 with actual EF1A genotype partitions. Misassignments were directed to

629 maintain (nearly) equal sample sizes in the two groups. Histogram bars in purple

630 indicate reassignment of a single library; orange represents reciprocal swap of

631 single libraries across partitions. Grey represents reciprocal swap of two

632 libraries across genotype partitions. Partitioning of individuals by EF1A

633 genotype suggests a stronger signal (vertical dotted line) than almost all

634 permutations; 'misassignments' with more extreme results always involve

635 reassignment of wild individual Po5. The maximal observation shown (447

636 differentially expressed fragments) represents Po5 as an ins heterozygote

637 instead.

638 
639 Figure 3. Volcano plot of transcripts that are differentially expressed between

640 EF1A genotypes (FDR < 0.01). Contrast indicated with positive logFC values on

641 the right for fragments that have higher expression in wild homozygotes. Panel

642 (A) includes all individuals in study; right panel (B) excludes wild individual Po5.

643 Red dotted lines indicate FDR of 0.01.

644

645 Figure 4. Reaction by genotype to increased water temperature in $P$. ochraceus.

646 In panel A, 46 fragments exhibit significant (FDR $<0.01)$ differential expression

647 between ambient and elevated temperatures in wild homozygotes. In panel B, 6

648 fragments exhibit significant (FDR $<0.01)$ differential expression after

649 temperature treatment in ins heterozygotes.

650 
Figure 1

Figure 1. Image of Pisaster ochraceus

Aboral view of Pisaster in righting response trial. Photo by JPW.

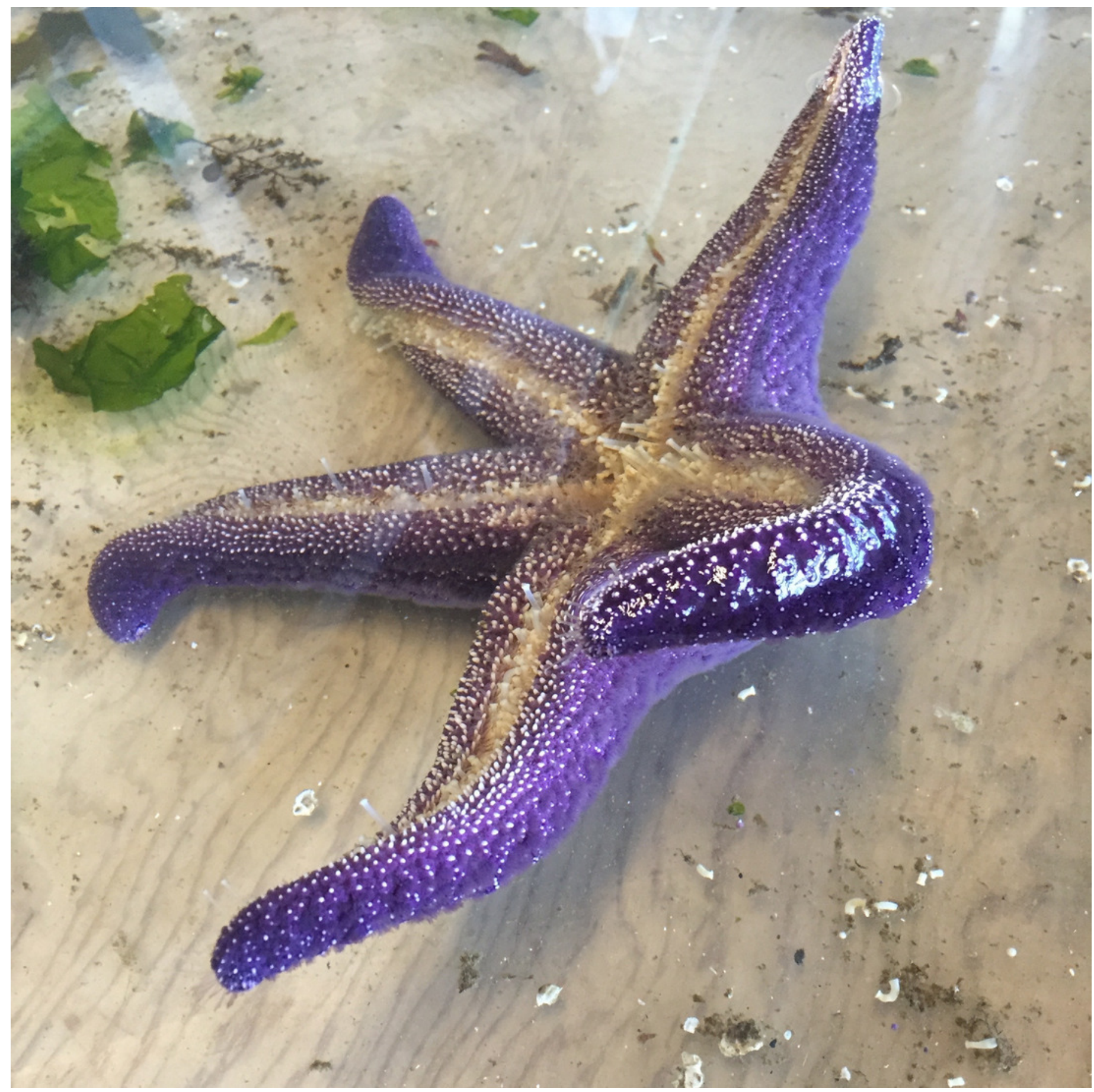




\section{Figure 2 (on next page)}

Figure 2. Randomized expression differences among libraries

Sorted permutational misassignment of individuals and comparison with actual EF1A genotype partitions. Misassignments were directed to maintain (nearly) equal sample sizes in the two groups. Histogram bars in purple indicate reassignment of a single library; orange represents reciprocal swap of single libraries across partitions. Grey represents reciprocal swap of two libraries across genotype partitions. Partitioning of individuals by EF1A genotype suggests a stronger signal (vertical dotted line) than almost all permutations;

'misassignments' with more extreme results always involve reassignment of wild individual P05. The maximal observation shown (447 differentially expressed fragments) represents Po5 as an ins heterozygote instead. 


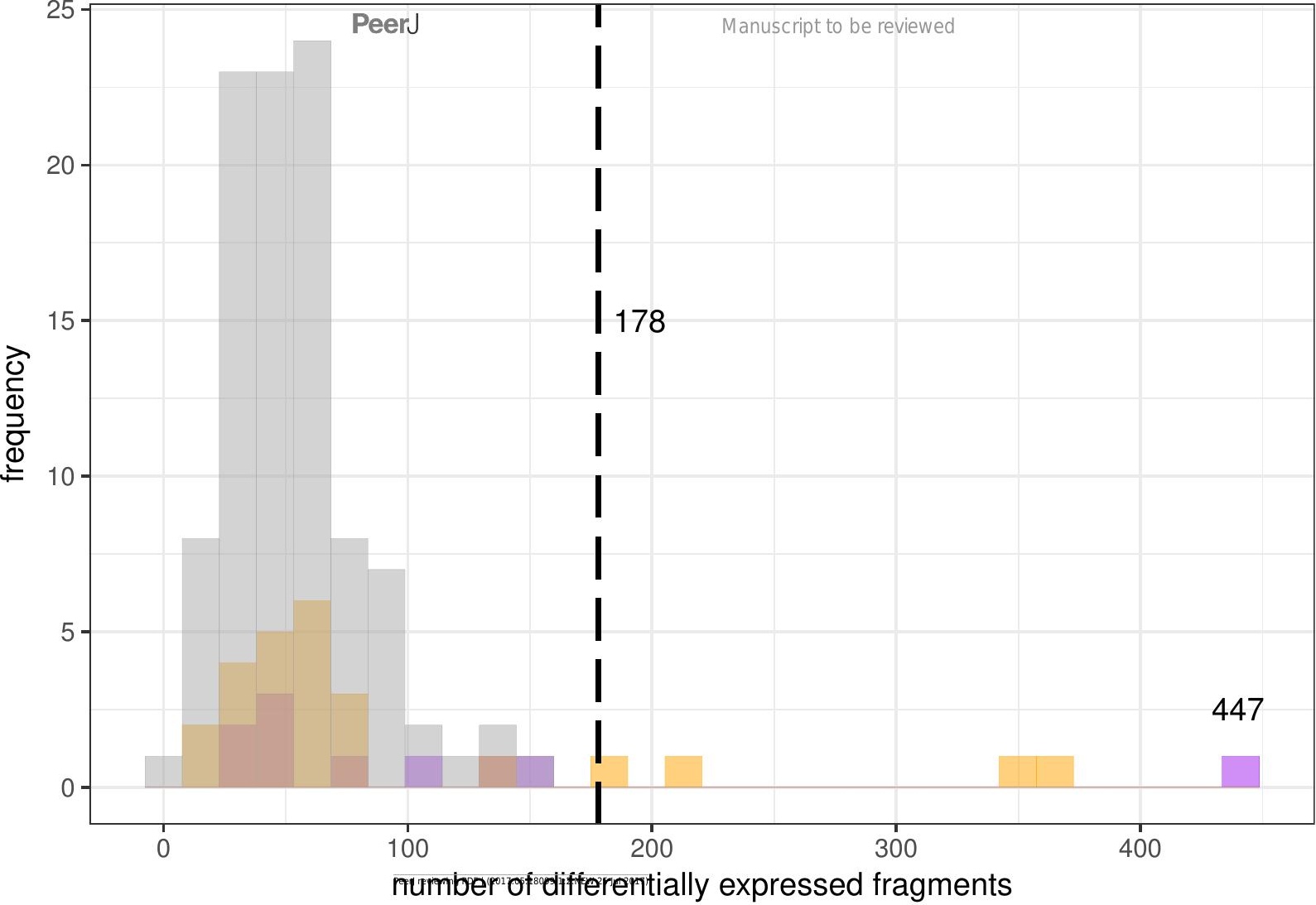


Figure 3 (on next page)

Figure 3. Heatmap of differential expression

Volcano plot of transcripts that are differentially expressed between EF1A genotypes (FDR < 0.01). Contrast indicated with positive logFC values on the right for fragments that have higher expression in wild homozygotes. Panel (A) includes all individuals in study; right panel (B) excludes wild individual Po5. Red dotted lines indicate FDR of 0.01 . 
Figure 4 (on next page)

Figure 4. Volcano plots of differential expression

Reaction by genotype to increased water temperature in $P$. ochraceus. In panel A, 46

fragments exhibit significant (FDR $<0.01$ ) differential expression between ambient and elevated temperatures in wild homozygotes. In panel B, 6 fragments exhibit significant (FDR $<0.01$ ) differential expression after temperature treatment in ins heterozygotes. 

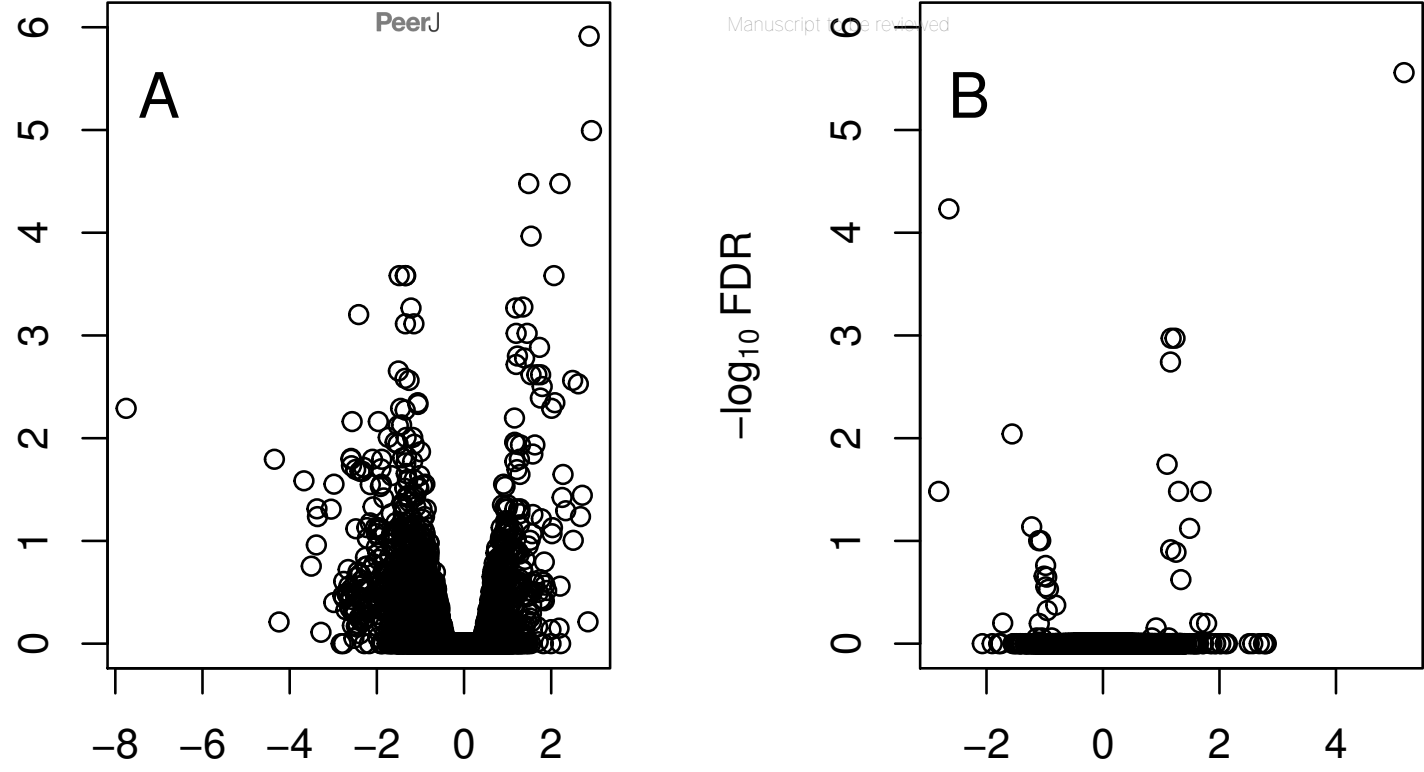

$\log _{2}$ fold change $\log _{2}$ fold change 